\title{
A Simple Phenothiazine Based Ratiometric Fluorescent Sensor for Hypochlorite Detection
}

\author{
Disha Soni, Kajol Yadav, Raghu Chitta* \\ Department of Chemistry, School of Chemical Sciences and Pharmacy, Central University of \\ Rajasthan, Bandarsindri, Tehsil: Kishangarh, Dist. Ajmer, Rajasthan-305817, India. \\ Email: raghuchitta@curaj.ac.in
}

\begin{abstract}
:
Hypochlorite ( $\mathrm{ClO}^{-}$), an important reactive oxygen species (ROS), plays an important role in immune system. $\mathrm{ClO}^{-}$is widely used as a disinfectant for treatment of water and other household purposes. Hence there is a need to develop highly sensitive and selective molecular probes for the detection of $\mathrm{ClO}^{-}$in environmental and biological systems. Here, a simple phenothiazine based ratiometric fluorescent sensor PTZ-Ph for hypochlorite detection is presented. The detection limit of $0.36 \mu \mathrm{M}$ was calculated. This probe was found to be selective for $\mathrm{NaOCl}$ as compared to other ROS, anions, and cations and also in presence of various interferents. Formation of sulfoxide was evident from the NMR titration experiment.
\end{abstract}

Key words: Ratiometric, fluorescent sensing, phenothiazine, hypochlorite, detection limit.

\section{Introduction}

There is a great need to develop sensors for various cations, anions, and ROS, which play an important role in biological systems and environment. Fluorescence is the most advantageous amongst various techniques due to its high sensitivity, relatively low costs, fast response time, and its easy implementation. Ratiometric sensing has an inherent benefit due to the emission intensity being monitored at two different wavelengths, which helps to eliminate the factors affecting the quantitative measurements like illumination intensity and optical path length. [1] Hypochlorite, when produced in excessive amounts in the body can cause tissue injury and many diseases. [2] Therefore, a ratiometric fluorescent sensor PTZ-Ph was synthesized and applied for selective and sensitive detection of hypochlorite.

\section{Results and Discussion}

All the sensing studies were carried out in $\mathrm{MeOH}$ :PBS buffer (2:3 v/v). The probe PTZ-Ph displayed the absorption peaks at 233, 264, and $314 \mathrm{~nm}$. Upon addition of hypochlorite, the absorbance at 233 and $314 \mathrm{~nm}$ increased and a new peak at $285 \mathrm{~nm}$ was observed (Fig.1), which might be due to the oxidized product. The steady state fluorescence studies were performed to establish sensitivity and selectivity

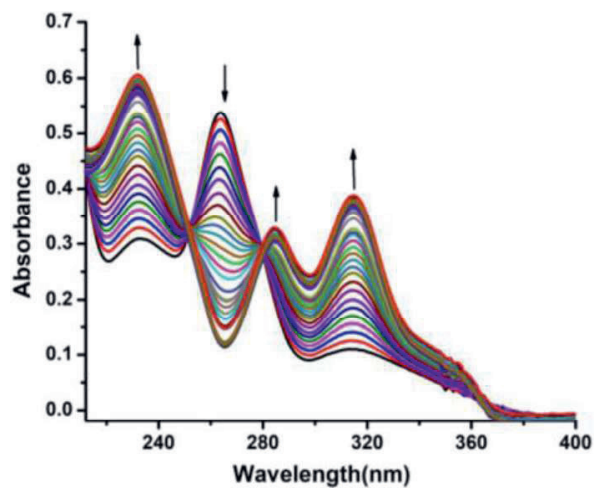

Fig.1 Absorption titration spectra of PTZ-Ph $\left(1.94 \times 10^{-5} \mathrm{M}\right)$ upon addition of $\mathrm{NaOCl}$ solution $\left(2 \times 10^{-3} \mathrm{M}\right)$

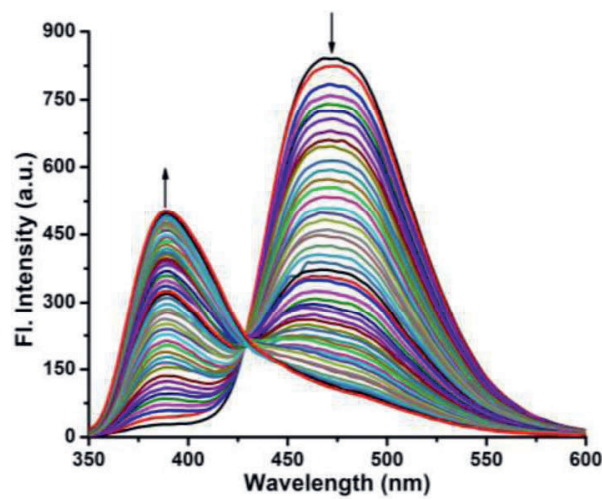

Fig.2 Fluorescence spectra of PTZ-Ph $\left(1 \times 10^{-6} \mathrm{M}\right)$ upon addition of $\mathrm{NaOCl}$ solution $\left(4.7 \times 10^{-5} \mathrm{M}\right) \cdot \lambda_{\text {ex: }} 320$ $n m$. 
of the probe. The fluorescence spectra of PTZ$\mathbf{P h}$, when excited at $320 \mathrm{~nm}$ showed a maximum peak at $473 \mathrm{~nm}$ but upon addition of incremental amounts of sodium hypochlorite solution, the emission at $473 \mathrm{~nm}$ started decreasing and a new peak at $388 \mathrm{~nm}$ started arising, depicting the ratiometric response of the probe (Fig.2). A calibration curve was plotted (Fig.3) and the detection limit was calculated to be $0.36 \mu \mathrm{M}$.

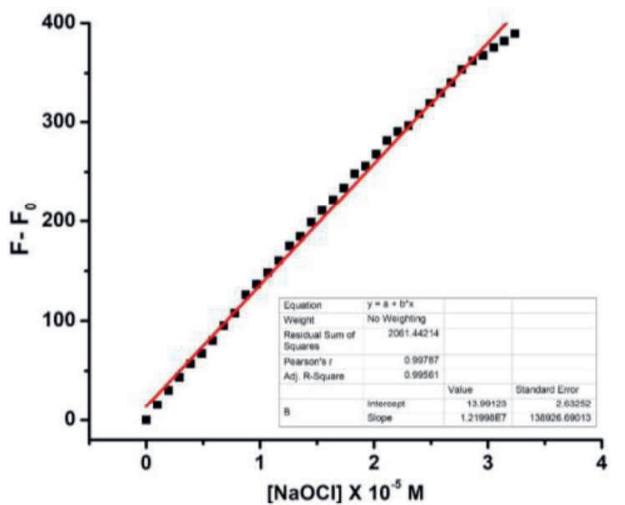

Fig. 3 Calibration curve for the detection limit calculation.

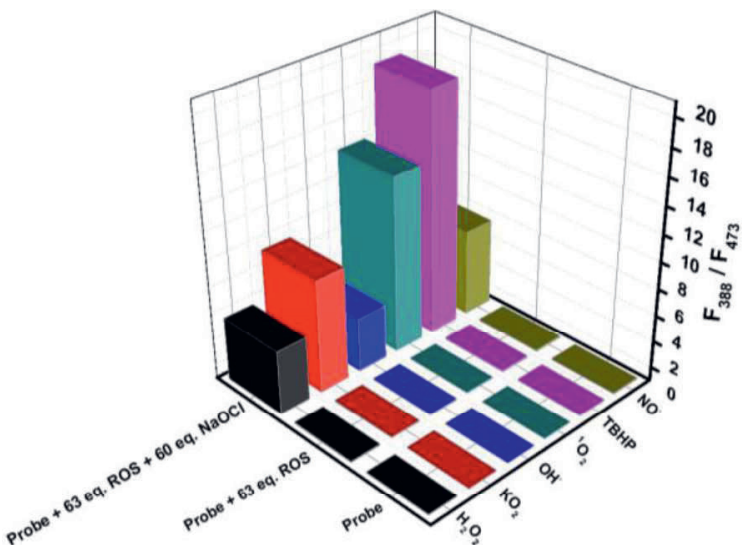

Fig. 4 Bar graph depicting the effect of ROS on PTZPh $\left(1 \times 10^{-6} \mathrm{M}\right)$ probe and hypochlorite in presence of ROS ( $\lambda_{\text {ex: }} 320 \mathrm{~nm}$ ).

A time-dependent study was also performed with PTZ-Ph and $\mathrm{NaOCl}$ added, and it was found that the emission intensity was almost constant for 30 minutes.

To establish the selectivity of PTZ-Ph probe, the probe solution was treated with various
ROS, anions, and cations. Only hypochlorite could induce the changes in the emission intensity. Next, competitive studies were also performed. The emission of probe on the addition of hypochlorite was monitored in presence of interferents and it was observed that hypochlorite could react with probe without being affected by any interferents (Fig. 4). This demonstrated the efficiency of probe PTZ-Ph for its application in complex biological and environmental systems.

To determine the species responsible for fluorescence enhancement, we synthesized the sulfoxide counterpart of the probe PTZ-Ph-O and recorded its NMR spectrum. NMR titration experiment was carried out by adding aliquots of $\mathrm{NaOCl}$ solution in PTZ-Ph in $\mathrm{CD}_{3} \mathrm{OD}$. It was observed that NMR of PTZ-Ph-O exactly matched with final titration spectrum, establishing sulfoxide as the major species being formed upon addition of $\mathrm{NaOCl}$.

\section{Conclusion}

A ratiometric fluorescent probe PTZ-Ph was synthesized and used for hypochlorite detection. The detection limit was calculated to be $0.36 \mu \mathrm{M}$. NMR titration showed the formation of sulfoxide upon addition of $\mathrm{NaOCl}$ solution. It was also selective over other ROS, cations, and anions. NMR titrations showed the formation of sulfoxide as the major species. Computational, $\mathrm{pH}$-dependent, and biological studies are in progress.

\section{References}

[1] J. Du, J. Fan, X. Peng, H. Li, S. Sun, The Quinoline Derivative of Ratiometric and Sensitive Fluorescent Zinc Probe Based on Deprotonation Sens. Actuators, B 144, 337-341 (2010).

[2] G. P. Li, D. J. Zhu, Q. Liu, L. Xue, H. Jiang, A Strategy for Highly Selective Detection and Imaging of Hypochlorite Using Selenoxide Elimination Org. Lett. 15, 2002-2005 (2013). 